University of Wollongong

Research Online

Faculty of Arts, Social Sciences and Humanities

- Papers

Faculty of Arts, Social Sciences \& Humanities

January 2020

\title{
A systematic review and meta-analysis of published research data on COVID-19 infection fatality rates
}

Gideon Meyerowitz-Katz

University of Wollongong, gsmk133@uowmail.edu.au

Lea Merone

Follow this and additional works at: https://ro.uow.edu.au/asshpapers

Research Online is the open access institutional repository for the University of Wollongong. For further information contact the UOW Library: research-pubs@uow.edu.au 


\title{
A systematic review and meta-analysis of published research data on COVID-19 infection fatality rates
}

\author{
Abstract \\ 2020 An important unknown during the coronavirus disease-2019 (COVID-19) pandemic has been the \\ infection fatality rate (IFR). This differs from the case fatality rate (CFR) as an estimate of the number of \\ deaths and as a proportion of the total number of cases, including those who are mild and asymptomatic. \\ While the CFR is extremely valuable for experts, IFR is increasingly being called for by policy makers and \\ the lay public as an estimate of the overall mortality from COVID-19. Methods: Pubmed, Medline, SSRN, \\ and Medrxiv were searched using a set of terms and Boolean operators on 25/04/2020 and re-searched \\ on 14/05/2020, 21/05/2020 and 16/06/2020. Articles were screened for inclusion by both authors. Meta- \\ analysis was performed in Stata 15.1 by using the metan command, based on IFR and confidence \\ intervals extracted from each study. Google/Google Scholar was used to assess the grey literature \\ relating to government reports. Results: After exclusions, there were 24 estimates of IFR included in the \\ final meta-analysis, from a wide range of countries, published between February and June 2020 . The \\ meta-analysis demonstrated a point estimate of IFR of $0.68 \%(0.53 \%-0.82 \%)$ with high heterogeneity $(p<$ \\ 0.001). Conclusion: Based on a systematic review and meta-analysis of published evidence on COVID-19 \\ until July 2020 , the IFR of the disease across populations is $0.68 \%(0.53 \%-0.82 \%)$. However, due to very \\ high heterogeneity in the meta-analysis, it is difficult to know if this represents a completely unbiased \\ point estimate. It is likely that, due to age and perhaps underlying comorbidities in the population, \\ different places will experience different IFRs due to the disease. Given issues with mortality recording, it \\ is also likely that this represents an underestimate of the true IFR figure. More research looking at age- \\ stratified IFR is urgently needed to inform policymaking on this front.

\section{Publication Details} \\ Meyerowitz-Katz, G. \& Merone, L. (2020). A systematic review and meta-analysis of published research \\ data on COVID-19 infection fatality rates. International Journal of Infectious Diseases, 101 138-148.
}

This journal article is available at Research Online: https://ro.uow.edu.au/asshpapers/359 


\title{
A systematic review and meta-analysis of published research data on COVID-19 infection fatality rates
}

\author{
Gideon Meyerowitz-Katz ${ }^{\mathrm{a}, \mathrm{b}, *}$, Lea Merone ${ }^{\mathrm{c}, \mathrm{d}}$ \\ a Western Sydney Local Health District, Australia \\ ${ }^{\mathrm{b}}$ University of Wollongong, Australia \\ 'James Cook University, Australia \\ d Tropical Public Health Service, Cairns, Australia
}

\section{A R T I C L E I N F O}

\section{Article history:}

Received 8 July 2020

Received in revised form 20 September 2020

Accepted 24 September 2020

\section{Keywords:}

COVID-19

SARS-CoV-2

Infection-fatality rate

Global health

Death rate

\begin{abstract}
A B S T R A C T
An important unknown during the coronavirus disease-2019 (COVID-19) pandemic has been the infection fatality rate (IFR). This differs from the case fatality rate (CFR) as an estimate of the number of deaths and as a proportion of the total number of cases, including those who are mild and asymptomatic. While the CFR is extremely valuable for experts, IFR is increasingly being called for by policy makers and the lay public as an estimate of the overall mortality from COVID-19.

Methods: Pubmed, Medline, SSRN, and Medrxiv were searched using a set of terms and Boolean operators on 25/04/2020 and re-searched on 14/05/2020, 21/05/2020 and 16/06/2020. Articles were screened for inclusion by both authors. Meta-analysis was performed in Stata 15.1 by using the metan command, based on IFR and confidence intervals extracted from each study. Google/Google Scholar was used to assess the grey literature relating to government reports.

Results: After exclusions, there were 24 estimates of IFR included in the final meta-analysis, from a wide range of countries, published between February and June 2020.

The meta-analysis demonstrated a point estimate of IFR of $0.68 \%(0.53 \%-0.82 \%)$ with high heterogeneity $(\mathrm{p}<0.001)$.

Conclusion: Based on a systematic review and meta-analysis of published evidence on COVID-19 until July 2020 , the IFR of the disease across populations is $0.68 \%(0.53 \%-0.82 \%)$. However, due to very high heterogeneity in the meta-analysis, it is difficult to know if this represents a completely unbiased point estimate. It is likely that, due to age and perhaps underlying comorbidities in the population, different places will experience different IFRs due to the disease. Given issues with mortality recording, it is also likely that this represents an underestimate of the true IFR figure. More research looking at age-stratified IFR is urgently needed to inform policymaking on this front.
\end{abstract}

(C) 2020 Published by Elsevier Ltd on behalf of International Society for Infectious Diseases. This is an open

access article under the CC BY-NC-ND license (http://creativecommons.org/licenses/by-nc-nd/4.0/).

\section{Introduction}

The year 2020 saw the emergence of a global pandemic, coronavirus disease-2019(COVID-19), caused by the SARS-CoV-2 virus, which began in China and has since spread across the world. One of the most challenging questions to answer during the COVID-19 pandemic has been regarding the true infection fatality rate (IFR) of the disease. While case fatality rates (CFR) are eminently calculable from various published data sources (Kahathuduwa et al., 2020) - CFR being the number of deaths divided by the number of confirmed cases - it is far more difficult to extrapolate to the proportion of all infected individuals who have died

\footnotetext{
* Corresponding author at: University of Wollongong, Australia

E-mail address: gideon.meyerowitzkatz@health.nsw.gov.au (G. Meyerowitz-Katz).
}

due to the infection because those who have very mild, atypical or asymptomatic disease are frequently left undetected and therefore omitted from fatality rate calculations (Rinaldi and Paradisi, 2020). Given the issues with obtaining accurate estimates, it is not unexpected that there are wide disparities in the published estimates of case numbers. This is an issue for several reasons, most importantly in that policy is dependent on modelling, and modelling is dependent on assumptions. If we do not have a robust estimate of IFR, it is challenging to make predictions about the true impact of COVID-19 in any given susceptible population, which may stymie policy development and may have serious consequences for decision-making into the future. While CFR is a more commonly used statistic, and is very widely understood among experts, IFR provides important context for policymakers that is hard to convey, particularly given the wide variation in CFR estimates. While CFR is naturally a function of the denominator - i.e. how many people have been tested for the disease - policymakers are often most 
interested in the total burden in the population rather than the biased estimates given from testing only the acutely unwell patients.

This is particularly important when considering the reopening of countries post 'lockdown'. Depending on the severity of the disease, it may be reasonable to reopen services such as schools, bars, and clubs, at different timings. Another salient point is the expected burden of disease in younger age groups - while there are likely long-term impacts other than death, it will be important for future planning to know how many people in various age groups are likely to die if the infection becomes widespread across societies. Age-stratified estimates are also important as it may give countries some way to predict the number of deaths expected given their demographic breakdown.

There are a number of methods for investigating the IFR in a population. Retrospective modelling studies of influenza, as a common cause of global pandemics, have successfully predicted the true number of cases and deaths from influenza-like illness records and excess mortality estimates (Wong et al., 2013; Thompson et al., 2009). However, these may not be accurate, in part due to the general difficulty in attributing influenza cases to subsequent mortality, meaning that CFRs may both overestimate and equally underestimate the true number of deaths due to the disease in a population (Spychalski et al., 2020).

The standard test for COVID-19 involves polymerase chain reaction (PCR) testing of nasopharyngeal swabs from patients suspected of having contracted the virus. This can produce some false negatives (Anon, 2020a), with one study demonstrating almost a quarter of patients experiencing a positive result following up to two previous false negatives (Xiao et al., 2020). The sensitivity of PCR is believed to be around $70 \%$, which may lead to the underdiagnosis of COVID-19 (Fernández-Barat et al., 2020). PCR is also limited in that it cannot test for previous infection. Serology testing is more invasive, requiring a blood sample. However, it can determine whether there has been previous infection and can be performed rapidly at the point of care (PoC). Serology PoC testing cannot determine if a person is infectious or if infection is recent and there is a risk of misinterpretation of results (Winter and Hegde, 2020). Generally, serology testing is more sensitive and specific than PCR, but will still likely overestimate prevalence when few people have been infected with COVID-19 and underestimate in populations with more infections (Lisboa Bastos et al., 2020). Additionally, there has been great variation noted in the sensitivity, the ability of the test to detect truly positive cases, of COVID-19 serology tests (Ghaffari et al., 2020). Serological tests are reliant on seroconversion, which in COVID-19 occurs several days after the viral load has peaked, meaning serology is less effective in the earlier stages of the disease (Ghaffari et al., 2020). Some studies suggest that there are those who do not seroconvert at all (Staines et al., 2020). The lack of reliable testing may be problematic for estimating CFRs and IFRs.

Given the emergence of COVID-19 as a global pandemic, it is somewhat unlikely that these issues are entirely the same for the newer disease, but there are likely similarities between the two. Some analysis in mainstream media publications and pre-prints has implied that there is a large burden of deaths that remains unattributed to COVID-19. Similarly, serological surveys have demonstrated that there is a large proportion of cases that have not been captured in the case numbers reported in the US, Europe and potentially worldwide (Bendavid et al., 2020; Erikstrup et al., 2020; Simon, 2020).

This paper presents a systematic effort to collate and aggregate these disparate estimates of IFR using an easily replicable method. While any meta-analysis is only as reliable as the quality of included studies, this will at least put a realistic estimate to the IFR given current published evidence.

\section{Methods}

This study used a simple systematic review protocol. PubMed, MedLine, and Medrxiv were searched on the 25/04/2020 using the terms and Boolean operators: (infection fatality rate OR ifr OR seroprevalence) AND (COVID-19 OR SARS-CoV-2). This search was repeated on $14 / 05 / 2020,25 / 05 / 2020$ and 16/06/2020. The pre-print server SSRN was also searched on 25/05/2020; however, as it does not allow this format, the Boolean operators and brackets were removed. While Medrxiv and SSRN would usually be excluded from systematic review, given that the papers included

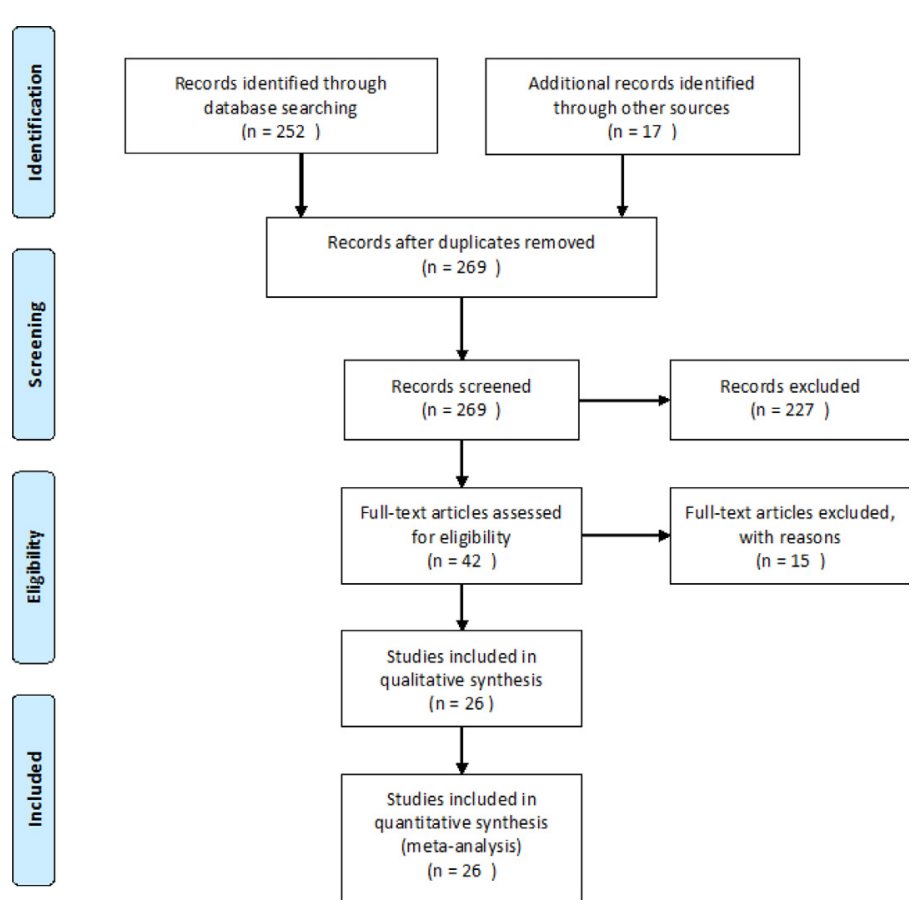


Table 1

Results of the systematic review of published research data on COVID-19 infection fatality rates.

\begin{tabular}{|c|c|c|c|c|}
\hline Study & Location & Study period & Method and sample size & Results \\
\hline Bassett (2020) & $\begin{array}{l}\text { New York (NYC) } \\
\text { (USA), Madrid, } \\
\text { Lombardy }\end{array}$ & $\begin{array}{l}\text { Until 22nd April } 2020 \\
\text { (commence date not } \\
\text { provided) }\end{array}$ & $\begin{array}{l}\text { Utilised } R_{0} \text { of } 2.4 \text { to calculate a predicted infection } \\
\text { rate of } 81 \% \text { (UK and USA). }\end{array}$ & $\begin{array}{l}\text { Over the } 3 \text { regions, the IFR (using predicted total } \\
\text { infection rate of } 81 \% \text { ) was calculated at } 0.17 \% \text {, for } \\
\text { each region specifically, using the same predicted } \\
\text { infection rate: NYC } 0.22 \% \text {, Lombardy } 0.15 \% \text { and } \\
\text { Madrid } 0.14 \% \text {. }\end{array}$ \\
\hline $\begin{array}{l}\text { Bendavid et al. } \\
\text { (2020) }\end{array}$ & $\begin{array}{l}\text { Santa-Clara } \\
\text { Country }\end{array}$ & 2 days & $\begin{array}{l}\text { Serological testing of } 3300 \text { local adults and } \\
\text { children. Volunteer sampling. Bootstrap } \\
\text { procedure used for weighted and unweighted } \\
\text { prevalence estimates. }\end{array}$ & $\begin{array}{l}\text { Crude prevalence rate } 1.5 \% \text { ( } 95 \% \text { CI } 1.1 \%-2.0 \% \text { ), } \\
\text { unweighted population prevalence } 1.2 \% \\
\text { (bootstrap } 95 \% \text { CI } 0.7 \%-1.8 \% \text { ), weighted } \\
\text { population prevalence } 2.8 \% \text { ( } 95 \% \text { CI } 1.3 \%-4.7 \% \text { ). } \\
\text { Number of infections estimated to be greater than } \\
\text { the number of recorded cases. IFR } 0.17 \% \text {. }\end{array}$ \\
\hline $\begin{array}{l}\text { Government of } \\
\text { the Czech } \\
\text { Republic }\end{array}$ & Czech Republic & $\begin{array}{l}\text { Unspecified start date, } \\
\text { concluded 1st May } 2020\end{array}$ & Tested 26,549 people for antibodies (serology). & Uncovered 107 new cases. \\
\hline $\begin{array}{l}\text { Government of } \\
\text { Denmark }\end{array}$ & Denmark & Reported on 20th May 2020 & $\begin{array}{l}\text { Tested } 1,071 \text { people out of a total sample of } 2600 \\
\text { for antibodies. }\end{array}$ & $\begin{array}{l}\text { An estimated } 1.1 \% \text { seroprevalence, with a } \\
\text { confidence interval ranging from } 0.5 \% \text { to } 1.8 \% \text {. }\end{array}$ \\
\hline $\begin{array}{l}\text { Government of } \\
\text { England } \\
\text { (Office for }\end{array}$ & England, UK & As of 24th May 2020 & $\begin{array}{l}\text { Serology samples randomly gathered from } 885 \\
\text { people up until } 24 / 05 / 2020\end{array}$ & $\begin{array}{l}6.78 \%(5.21 \%-8.64 \%) \text { tested positive on serological } \\
\text { testing regimen. }\end{array}$ \\
\hline
\end{tabular}

Government Indiana, USA 7 days

Statistics)

(State) of

Indiana, USA

Government of Finland

Finland

Government of Slovenia

Slovenia

Government of All provinces of

Spain Spain

Government of Stockholm

Sweden county

Hallal et al. Brazil

(2020)

Herzog et al. Belgium

(2020)

Week 22

Not specified

27/04/2020-11/05/2020

27/04/2020-3/05/2020

(week 18)

Tested $>4600$ using viral PCR and serum for antibodies; 3600 randomly selected individuals

From 14th May to 21st May 2020

Two time periods in April, Total of 7307 samples from locations around with the estimate used in Belgium this paper from the $20-26$ of April 2020

Jung et al.

Cases exported (2020) from China and diagnosed outside China

Modi et al. Italy (1688

(2020a, towns)

2020b)

Nishiura et al. (2020)

Japanese

'evacuees' returning to Japan from Wuhan

Rinaldi and Northern Italy

Paradisi (10

16 days

Used data from $01 / 01 /$ 2015-28/03/2020

3 days

Utilised 5-year death data until April 2020

(2020)

Lombardy)

Roques et France

54 days

(2020)

Rosenberg et al. New York State, 9 days

(2020) USA

Russel et al.

Diamond

14-17 days

(2020)

Princess Cruise

Ship
14-17 days and 900 volunteers.

Random weekly sampling of the Finnish population, week 22 included 178 samples 1367 swabs and 1367 blood samples collected from a representative sample of the population. 60,983 participants invited, of which so far 37,992 (62.3\%) have responded

1200 weekly samples. Initial analysis was reported from 1104 samples.

46,011 attempts lead to a total of 25,025 samples across every region of Brazil.

A total of 51 cases diagnosed between 24/09/2020 and 09/02/2020. Data collected from government websites or media quoting government announcements.

Utilised data from the Italian Institute of Statistics. Compared death rates during the COVID-19 pandemic to previous death rates by age and region.

A total of 565 individuals screened for symptoms and tested for COVID-19 (PCR).

$1.7 \%$ tested positive for COVID-19 on PCR plus an additional $1.1 \%$ who tested positive for antibodies. Estimated IFR $0.1 \% .45 \%$ of positive cases report no symptoms.

5 positives from 178 lead to a $2.81 \%$ positive rate, ranging from $1.21 \%$ to $6.41 \%$.

41 people (3.1\%) tested positive for COVID-19 antibodies.

$5 \%$ positive on serology, with death rates varying by region. Calculated IFR between $1 \%-1.3 \%$ 7.3\% tested positive on serology in Stockholm county. Official government report estimates IFR at $0.6 \%(0.4 \%-1.1 \%)$ based on modelling and serological testing.

An overall seroprevalence of $1.39 \%$, with the authors reporting a calculated IFR of $1 \%$, although it was impossible to ascertain whether this accounted for right censoring.

193 out of 3397 samples tested positive, with a weighted overall seroprevalence of $3.1 \%$. Combined with death estimates, this produced an IFR of $1.1 \%$ overall

Mean time from illness onset to death was 20.2 days. Estimated incidence in China on 24/01/2020 was 4718 (95\%CI 3328-6278) and CFR 5.3\% (95\%Cl $3.5 \%-7.6 \%)$. IFR $0.5 \%-0.8 \%$.

Clear increase in deaths was noted for early 2020. IFR increases with age. Range $0.02 \%$ ( $40-49$ years old) to $15.1 \%$ ( $>90$ years old).

A total of 8 passengers tested PCR positive for COVID-19 (1.4\%). Estimated ascertainment rate of 9.2\%. Estimated IFR 0.3\%-0.6\%.

Collected data from the Italian Institute of Statistics. The total population of the included municipalities was 50563. Bayesian model used to estimate IFR.

Obtained data on positive cases and deaths from Johns Hopkins University Centre for Systems Science and Engineering and data on tests performed from Santé Publique France, deaths from nursing homes were added to the official count.

Cross-sectional Seroprevalence study of 15,101 adults. Used IgG immunoassay approved for COVID-19

Deaths between February and April 2020 were 5fold the 2015-2019 average (341 versus 70). IFR $1.29 \%$ ( $95 \%$ CI $0.89-2.01$ ), increasing to $4.25 \%$ for those $>60$ years old $(95 \%$ CI $3.01 \%-6.39 \%)$

Calculated IFR $0.5 \%$ (95\%CI 0.3-0.8), when nursing home residents were adjusted for estimated IFR $0.8 \%$ (95\%CI 0.45-1.25). Estimated ratio between those actually infected and those observed was 8 (95\%CI 5-12).

$12.5 \%$ of specimens were reactive. Cumulative incidence was noted to be higher in Hispanic people, African-American people and nonHispanic Asian people.

A total of 3711 passengers and staff were tested There were 619 confirmed cases (17\%), 318 of (PCR) whilst in quarantine. Utilised data from the whom were asymptomatic (51\%). Corrected CFR World Health Organisation situational reports. was 2.6\% (95\%CI $0.89 \%-6.7 \%)$. Corrected IFR was $1.3 \%$ (95\%CI $0.38 \%-3.6 \%)$. CFR increased with age (3.6\% for those aged $60-69$ years, $95 \% \mathrm{CI} 3.2-4.0$ ) and $14.8 \%$ for those $>80$ years, $95 \% \mathrm{CI} 13.0-16.7$ ). 
Table 1 (Continued)

\begin{tabular}{|c|c|c|c|c|}
\hline Study & Location & Study period & Method and sample size & Results \\
\hline $\begin{array}{l}\text { Salje et al. } \\
\text { (2020) }\end{array}$ & $\begin{array}{l}\text { France (hospital } \\
\text { data) and } \\
\text { Diamond } \\
\text { Princess Cruise } \\
\text { Ship }\end{array}$ & $\begin{array}{l}\text { Data available up to } 7 \text { th } \\
\text { May } 2020\end{array}$ & $\begin{array}{l}\text { Modelling analysis of COVID-19 transmission in } \\
\text { France. This included 95,210 hospitalisations and } \\
719 \text { infections from the Diamond Princess Cruise } \\
\text { Ship. }\end{array}$ & $\begin{array}{l}3.6 \% \text { of infected individuals were hospitalised } \\
(95 \% \text { CI } 2.1 \%-5.6 \%) \text { and this percentage increased } \\
\text { with age and gender }(0.2 \% \text { females }<20 \text { years; } \\
45.9 \% \text { males }>80 \text { years). IFR } 0.7 \% \text { ( } 95 \% \text { CI } 0.4 \%- \\
1.0 \% \text { ) with a range } 0.001-10.1 \% \text {, increasing with } \\
\text { age. }\end{array}$ \\
\hline $\begin{array}{l}\text { Shakiba et al. } \\
\text { (2020) }\end{array}$ & Iran & 1 month & $\begin{array}{l}\text { Cluster randomised sampling utilised to obtain } \\
551 \text { rapid antibody tests for COVID- } 19\end{array}$ & $\begin{array}{l}22 \% \text { antibody seropositivity. } 18 \% \text { ( } 65 \text { subjects) } \\
\text { were asymptomatic. IFR } 0.08 \%-0.12 \% \text {. }\end{array}$ \\
\hline $\begin{array}{l}\text { Snoeck et al. } \\
\text { (2020) }\end{array}$ & Luxembourg & $\begin{array}{l}\text { Data collection } \\
\text { commenced on } 15 \text { April } \\
2020\end{array}$ & $\begin{array}{l}\text { Recruited voluntary residents of Luxembourg. } \\
\text { Performed PCR for COVID-19 in } 1842 \text { participants } \\
\text { and serology testing in } 1820 \text { participants. }\end{array}$ & $\begin{array}{l}\text { Low prevalence of carriers ( } 0.3 \%) \text {. Seroprevalence } \\
\text { of IgA was } 11 \% \text {, and } 2 \% \text { for IgG. Of } 1842 \text { PCR tests, } \\
\text { only } 6 \text { were inconclusive }(0.3 \%) \text {. Time prevalence } \\
\text { of COVID- } 19 \text { was } 0.32 \text { ( } 95 \% \text { CI } 0.02-0.63) \text {. }\end{array}$ \\
\hline $\begin{array}{l}\text { Streeck et al. } \\
\quad(2020)\end{array}$ & Germany & 7 days & $\begin{array}{l}\text { A sero-epidemiological CGP and GEP-compliant } \\
\text { study in a town exposed to a super-spreading } \\
\text { event. Utilised a questionnaire and PCR/serology } \\
\text { testing } 6 \text { weeks after outbreak. A sample of } 919 \\
\text { individuals had evaluable infection status. }\end{array}$ & $\begin{array}{l}\text { Infection rate or } 15.5 \% \text { ( } 95 \% \text { CI } 12.3 \%-19.0 \% \text { ); this } \\
\text { was } 5 \text {-fold reported cases in the community } \\
\text { (3.1\%). Estimated IFR } 0.36 \% \text { ( } 95 \% \text { CI } 0.29-0.45 \text { ). }\end{array}$ \\
\hline $\begin{array}{l}\text { Stringhini et al. } \\
\text { (2020a) }\end{array}$ & Switzerland & $\begin{array}{l}\text { Three serosurveys over } \\
\text { several time periods, with } \\
\text { the final results reported on } \\
\text { June 2nd }\end{array}$ & $\begin{array}{l}\text { Longitudinal serological survey, with an } \\
\text { accompanying paper estimating infection fatality } \\
\text { rate as well. }\end{array}$ & $\begin{array}{l}\text { Infection-fatality rate estimated by authors was } \\
0.64(0.38 \%-0.98 \%) \text { after correcting and } \\
\text { accounting for demography. }\end{array}$ \\
\hline $\begin{array}{l}\text { Tian et al. } \\
\text { (2020) }\end{array}$ & Beijing, China & 21 days & $\begin{array}{l}262 \text { cases retrospectively enrolled and } \\
\text { characteristics compared between severe, mild } \\
\text { and asymptomatic patients using Mann-Whitney } \\
\text { U tests and Wilcoxon tests. }\end{array}$ & $\begin{array}{l}\text { Five patients died and } 46 \text { were classified as } \\
\text { severe. IFR in Beijing was lower than nationally; } \\
0.9 \% \text { versus } 2.4 \%(p<0.001) \text {. }\end{array}$ \\
\hline $\begin{array}{l}\text { Verity et al. } \\
\text { (2020) }\end{array}$ & $\begin{array}{l}\text { Mainland China } \\
\text { and } 37 \text { countries } \\
\text { outside of } \\
\text { mainland China }\end{array}$ & 56 days & $\begin{array}{l}\text { Age-stratified CFR estimates on } 1334 \text { cases } \\
\text { outside mainland China. Used prevalence data } \\
\text { from PCR-confirmed cases in international } \\
\text { residents repatriated from China to determine } \\
\text { IFR. }\end{array}$ & $\begin{array}{l}\text { Mean time from illness onset to death } 17.8 \text { days } \\
\text { (95\%CI 16.9-19.2). CFR in China } 1.38 \% \text { ( } 95 \% \text { CI } \\
1.23-1.53 \text { ), increasing with age to } 6.8 \% \text { in those } \\
\text { aged }>65 \text { years ( } 95 \% \text { CI } 5.7 \%-7.2 \% \text { ) and } 13.4 \% \text { in } \\
\text { those aged }>80 \text { years }(95 \% \text { CI } 11.2 \%-15.9 \%) \text {. IFR } \\
0.66 \% \text { ( } 95 \% \text { CI } 0.39 \%-1.33 \%) \text {. }\end{array}$ \\
\hline $\begin{array}{l}\text { Villa et al. } \\
\text { (2020) }\end{array}$ & Italy & 32 days & $\begin{array}{l}\text { Collected data from Italy's Civil Protection Agency } \\
\text { from each of Italy's } 20 \text { regions. }\end{array}$ & $\begin{array}{l}\text { Estimated an IFR of } 1.1 \%(95 \% \text { CI } 0.2 \%-2.1 \%) \text { and a } \\
\text { CFR of } 12.7 \% \text {. }\end{array}$ \\
\hline
\end{tabular}

are not peer-reviewed, during the pandemic it has been an important source of information and contains many of the most recent estimates for epidemiological information about COVID-19. Inclusion criteria for the studies were:

\section{- Regarding COVID-19/SARS-CoV-2 (i.e. not SARS-CoV-1 extrap-} olations).

- Presented an estimated population IFR (or allowed the calculation of such from publicly available data).

Titles and abstracts were screened for eligibility and discarded if they did not meet the inclusion criteria. GMK then conducted a simple Google and Google Scholar search using the same terms to assess the grey literature, in particular published estimates from government agencies that may not appear on formal academic databases. LM assessed the articles to ensure congruence. If these met the inclusion criteria, they were included in the systematic review and meta-analysis. Similarly, Twitter searches were performed using similar search terms to assess the evidence available on social media. Estimates for IFR and the confidence interval were extracted for each study.

All analysis and data transformation were performed in Stata 15.1. The meta-analysis was performed using the metan command for continuous estimates, with IFR and the lower/upper bounds of the confidence interval as the variables entered. This model used the DerSimonian and Laird random-effects method. The metan command in Stata automatically generates an $\mathrm{I}^{2}$ statistic that was used to investigate heterogeneity. Histograms were visually inspected to ensure that there was no significant positive or negative skew to the results that would invalidate this methodology. For the studies where no confidence interval was provided, one was calculated.

A PRISMA flow diagram of the search methods.
Sensitivity analyses were performed stratifying the results into the type of study - serological vs non - by country, and by the month of calculation.

The metabias and metafunnel commands were used to examine publication bias in the included research, with Egger's test used for the metabias estimation. It was challenging to formally rate the risk of bias of the included modelling studies, as there was very significant heterogeneity in methodology and implementation, with the result that the risk of bias in these studies was considered to be high across all included research. Serological surveys were rated using the risk of bias in the prevalence tool with a resulting estimate in line with Cochrane GRADE criteria of low, moderate or high (Hoy et al., 2012). This tool asks a series of 10 questions about the sampling and data collection of prevalence studies, with a final rating based on the previous questions. Each question is answered yes/no, with a lack of information presumed to be no/unclear. A separate sensitivity analysis was conducted using only serological survey results stratified by the risk of bias.

Because of a recent surge in the number of serological surveys being published, these were included in the infection fatality estimate despite not formally calculating an IFR in the study text itself. Regional death rates were taken from the John Hopkins University CSSE dashboard (Dong et al., 2020) 10 days after the serosurvey completion where no IFR was calculated to account for right-censoring of these estimates (Giorgi Rossi et al., 2020), and used to estimate the IFR given the population.

All code and data files are available (in. do and. csv format) upon request.

\section{Results}

Initial searches identified 252 studies across all databases. Later searches on Google and social media, as well as resampling the 
included databases revealed a further 17 estimates to include in the study. These came from a variety of sources, with some appearing from blog posts, others posted on Twitter, and some government documents being found through Google. There were no duplicates specifically, however, two pre-prints had been published and so appeared in slightly different forms in both databases. In this case, the published study was used rather than the pre-print. Results are collated in Table 1.

Studies were excluded for a variety of reasons. Some studies only looked at COVID-19 incidence, rather than the prevalence of antibodies, and were thus considered potentially unreliable as population estimates (Gudbjartsson et al., 2020). The most common reason for exclusion was selection bias - many studies only looked at targeted populations in their seroprevalence data, and thus could not be used as population estimators of IFR (Erikstrup et al., 2020; Doi et al., 2020; Takita et al., 2020; Jerkovic et al., 2020; Valenti et al., 2020; Garcia-Basteiro et al., 2020; Fontanet et al., 2020; Thompson et al., 2020; Ed Slot and Reusken, 2020). For some data, it was difficult to determine the numerator (i.e. number of deaths) associated with the seroprevalence estimate or the denominator (i.e. population) was not well defined and thus we did not calculate an IFR (Silveira et al., 2020; Bryan et al., 2020). One study explicitly warned against using its data to obtain an IFR (Sood et al., 2020). Another study calculated an IFR, but did not allow for an estimate of confidence bounds and thus could not be included in the quantitative synthesis (Wilson, 2020).

After screening titles and abstracts, 227 studies were removed. Many of these looked at case fatality estimates or discussed IFR as a concept and/or a model input, rather than estimate the figure themselves. Forty papers were assessed for eligibility for inclusion in the study, which resulted in a final 25 to be included in the qualitative synthesis.

Studies varied widely in design, with 3 entirely modelled estimates (Nishiura et al., 2020; Jung et al., 2020; Salje et al., 2020), 4 observational studies (Bendavid et al., 2020; Verity et al., 2020; Tian et al., 2020; Russell et al., 2020), 5 pre-prints that were challenging to otherwise classify (Rinaldi and Paradisi, 2020; Roques et al., 2020; Villa et al., 2020; Modi et al., 2020a; Streeck et al., 2020), and a number of serological surveys of varying types reported by government agencies (Bassett, 2020; Anon, 2020b; IU, 2020; Snoeck et al., 2020; Slovenia RO, 2020; Anon, 2020c; Shakiba et al., 2020; Statistics OFN, 2020; Hallal et al., 2020; Institut SS, 2020; Folkhälsomyndigheten, 2020a; Anon, 2020e; Stringhini et al., 2020b). For the purposes of this research, an estimate for New York City was calculated from official statistics and the serosurvey; however, this was correlated with a published estimate (Wilson, 2020) to ensure validity.

\section{Meta-analysis of infection fatality rates of COVID-19 as of research published by 16/06/2020}

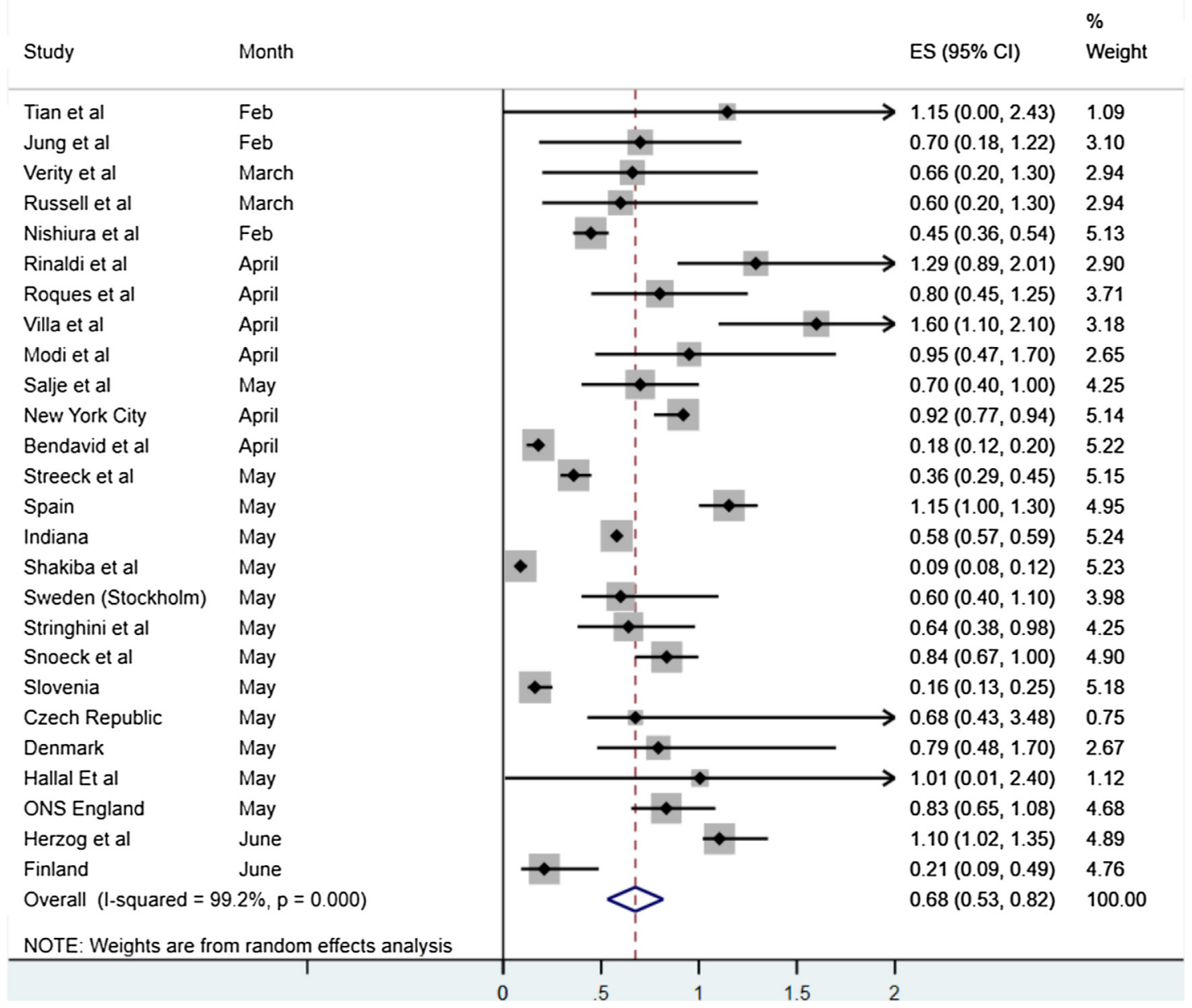

Figure 1. 
The main result from the random effects meta-analysis is presented in Figure 1. Overall, the aggregated estimate across all 24 studies indicated an IFR of $0.68 \%$ (95\% CI $0.53 \%-0.82 \%$ ), or 68 deaths per 10,000 infections. Heterogeneity was extremely high, with the overall $\mathrm{I}^{2}$ exceeding 99\% ( $\mathrm{p}<0.0001$ ) (Figure 2 ).

The monthly sensitivity analysis from Figure 3 showed that earlier estimates of IFR were lower, with later estimates showing a higher figure, although this appears to have stabilised in May.

Analysing by the region of origin did not appear to have a substantial effect on the findings, although there was a slightly lower estimate seen in Asia. As the Middle East was only represented by one study, this region was excluded from the meta-synthesis by region. Two studies were also excluded as they did not present an IFR for a specific region (i.e. Diamond Princess).

Of note, there was some difference in the estimates of IFR between estimates based on serosurveys and those of modelled or PCR-based estimates. The overall estimates from serosurvey studies were $0.60 \%(0.42 \%-0.77 \%)$, although again with very high heterogeneity, as can be seen in Figure 4.

There were insufficient data in the included research to perform a meta-analysis of IFR by age. However, qualitatively synthesizing the data that were presented indicates that the expected IFR below the age of 60 years is likely to be reduced by a large factor. This is supported by studies examining the CFR, which were not included in the quantitative synthesis and studies examining IFR in selected populations younger than 70 years of age that demonstrate a strong age-related gradient to the death rate from COVID-19.

Plotting the studies using a funnel plot produced some visual indication of publication bias, with more high estimates than would be expected; however, the Egger's regression was not significant $(\mathrm{p}=0.74)$.

\section{Risk of bias}

As previously noted, all estimates obtained from modelling studies are considered to be at a high risk of bias due to the heterogeneity and difficulty in rating these studies for accuracy. After using the rating 'risk of bias' tool for prevalence studies, 6 studies were considered to be at a low risk of bias, 4 studies at a moderate risk of bias, and the remaining 5 estimates at a high risk of bias. This is summarized in the table below (full scoring in Supplementary materials) (Table 2).

In general, the primary reason for down-rating studies was nonresponse bias, the lack of representativeness of the population sample, and a lack of information across all fields. Some reports

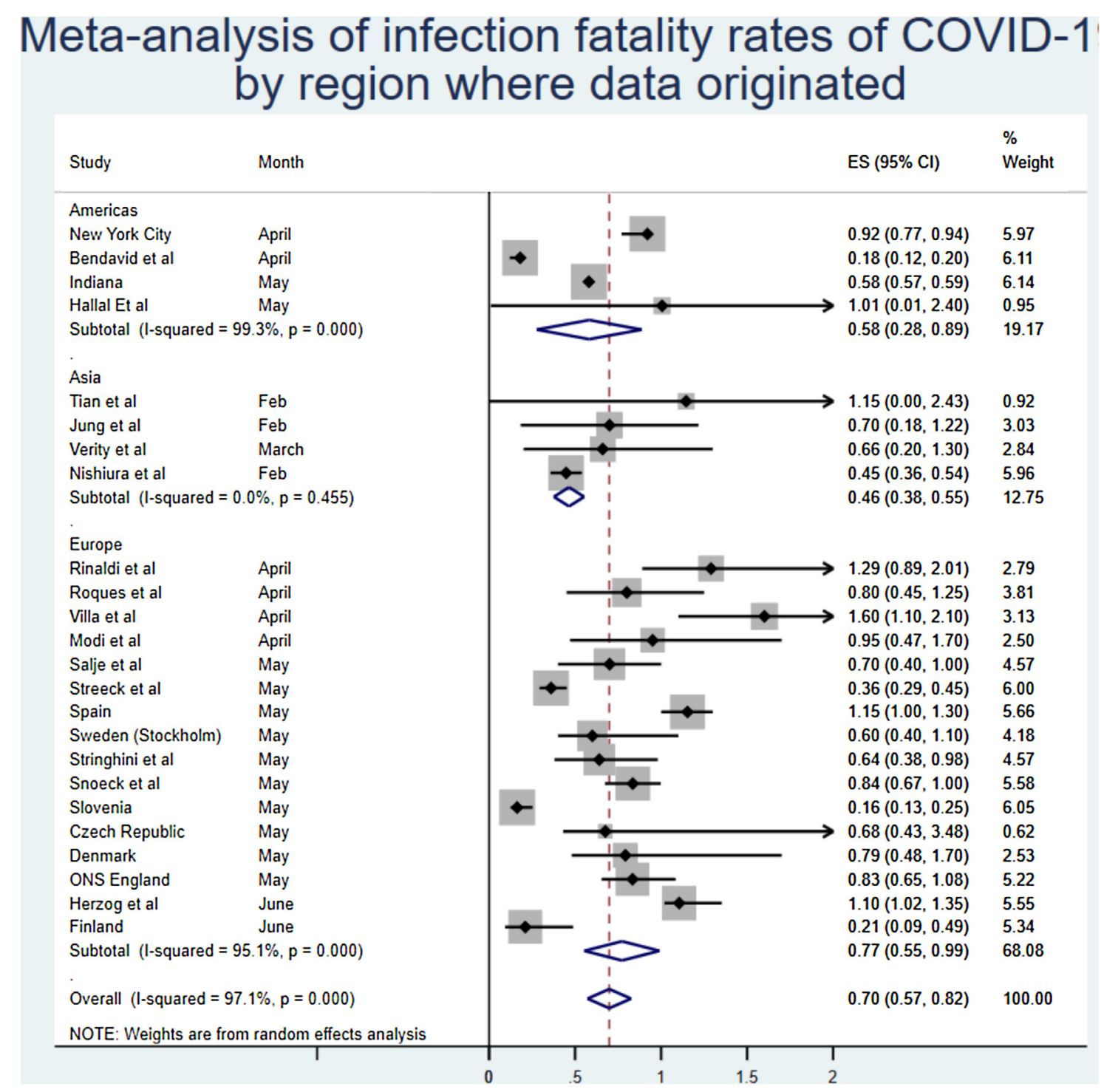

Figure 2. 


\section{Meta-analysis of infection fatality rates of COVID-19 by month of study publication}

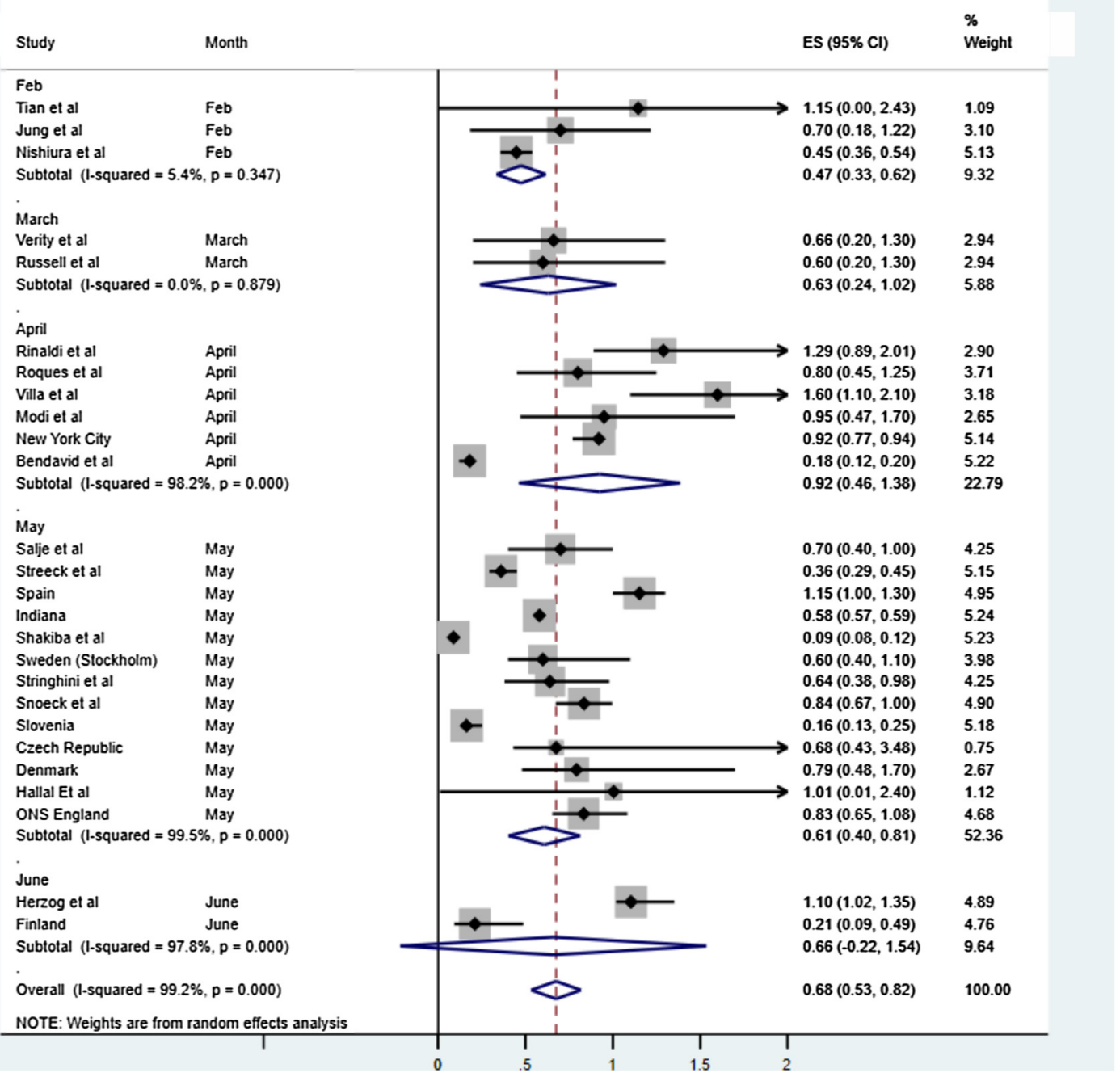

Figure 3.

were published with minimal information, which substantially increased the uncertainty and thus the risk of bias in these estimates.

The sensitivity analysis by study quality results are given below. Broadly, study quality was correlated with a higher inferred IFR, with lower-quality serosurveys reporting higher estimates of population prevalence than randomly sampled population-wide prevalence estimates. Restricting the analysis to only those studies at a low risk of bias resulted in modestly reduced heterogeneity and an increased IFR of $0.76 \%(0.37 \%-1.15 \%)$ (Figure 5 ).

\section{Other estimates of IFR}

Several estimates of IFR were identified but not included in the meta-analysis as they did not meet the inclusion criteria. The aggregated best estimate from the Centre for Evidence-Based Medicine at Oxford University of 0.1\%-0.41\% (Jason Oke, 2020), and the pre-print estimate reported by Grewelle and Leo of $1.04 \%$ $(0.77 \%-1.38 \%)$ (Grewelle and De Leo, 2020) were both pertinent but could not be included because of collinearity.

Similarly, the estimate of symptomatic IFR produced by Basu of $1.3 \%(0.6 \%-2.1 \%)$ (Basu, 2020) was excluded because of the exclusion of asymptomatic cases. Using reported estimates of asymptomatic cases, this estimate would likely match the metaanalytic IFR; however, this correction could not be applied for the estimates in this study as it could easily introduce bias in the results.

\section{Discussion}

As pandemic COVID-19 progresses, it is useful to use the IFR when reporting figures, particularly as some countries begin to engage in enhanced screening and surveillance, and observe an increase in positive cases that are asymptomatic and/or mild enough that they have so far avoided testing (Sutton et al., 2020). It has been acknowledged that COVID-19 is often spread from asymptomatic and/or very mildly symptomatic cases - potentially up to $50 \%$ of all patients - and that asymptomatic transmission may also be possible with COVID-19 (Nishiura et al., 2020; Bai et al., 2020) and the use of IFR would aid the capture of these individuals in mortality figures. IFR modelling, calculation and figures, however, are inconsistent.

The main finding of this research is that there is very high heterogeneity among estimates of IFR for COVID-19 and therefore, 


\section{Meta-analysis of infection fatality rates of COVID-19 by serology as of research published by $16 / 06 / 2020$}

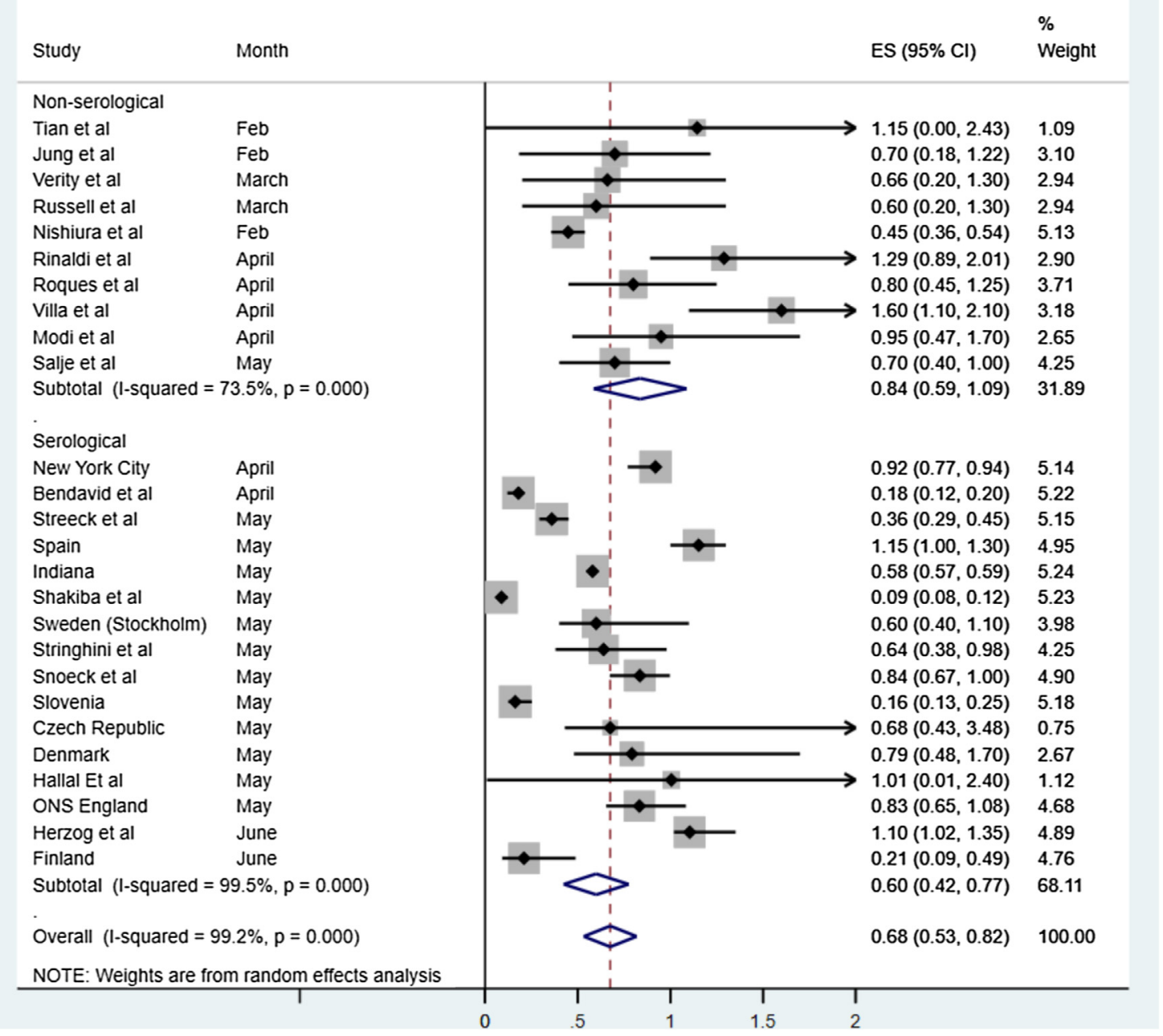

Figure 4 .

it is difficult to draw a single conclusion regarding the number. Aggregating the results together provides a point estimate of $0.68 \%$ $(0.53 \%-0.82 \%)$, but there remains considerable uncertainty about whether this is a reasonable figure or simply a best guess. It appears likely, however, that the true population IFR in most places from COVID-19 will lie somewhere between the lower bound and upper bounds of this estimate.

One reason for the very high heterogeneity is likely that different countries and regions will experience different death rates due to the disease. One factor that may impact this is government response, with more prepared countries suffering lower death rates than those that have sufficient resources to combat a large outbreak (Scally et al., 2020). Moreover, it is very likely, given the evidence around age-related fatality, that a country with a significantly younger population would see fewer deaths on average than one with a far older population, given similar levels of healthcare provisions between the two. For example, Israel, with a median age of 30 years, would expect a lower IFR than Italy, with a much higher median age ( 45.4 years).

Some included studies (Rinaldi and Paradisi, 2020; Modi et al., 2020a) compared fatality during COVID-19 pandemic with previous years' average fatality, determining that mortality has been higher during the pandemic and whilst correlation does not
Table 2

Risk of bias in included serosurveys.

\begin{tabular}{ll}
\hline Study & Overall risk of bias \\
\hline New York City & Moderate \\
Bendavid et al. & High \\
Streeck et al. & Low \\
Spain & Low \\
Indiana & High \\
Shakiba et al. & Moderate \\
Sweden (Stockholm) & Moderate \\
Stringhini et al. & Low \\
Wu et al. & High \\
Snoeck et al. & Low \\
Slovenia & High \\
Czech Republic & Low \\
Denmark & Moderate \\
Hallal et al. & Low \\
Herzog et al. & Moderate \\
Finland & Moderate \\
ONS England & Moderate \\
\hline
\end{tabular}

necessarily equate to causation, it is reasonable to link the events as causal given the high CFR observed across countries. It is highly likely from the data analysed that IFR increases with age group, with those aged over 60 years old experiencing the highest IFR, in 


\section{Meta-analysis of IFRs of COVID-19 from serosurveys by risk of bias as of research published by 16/06/2020}

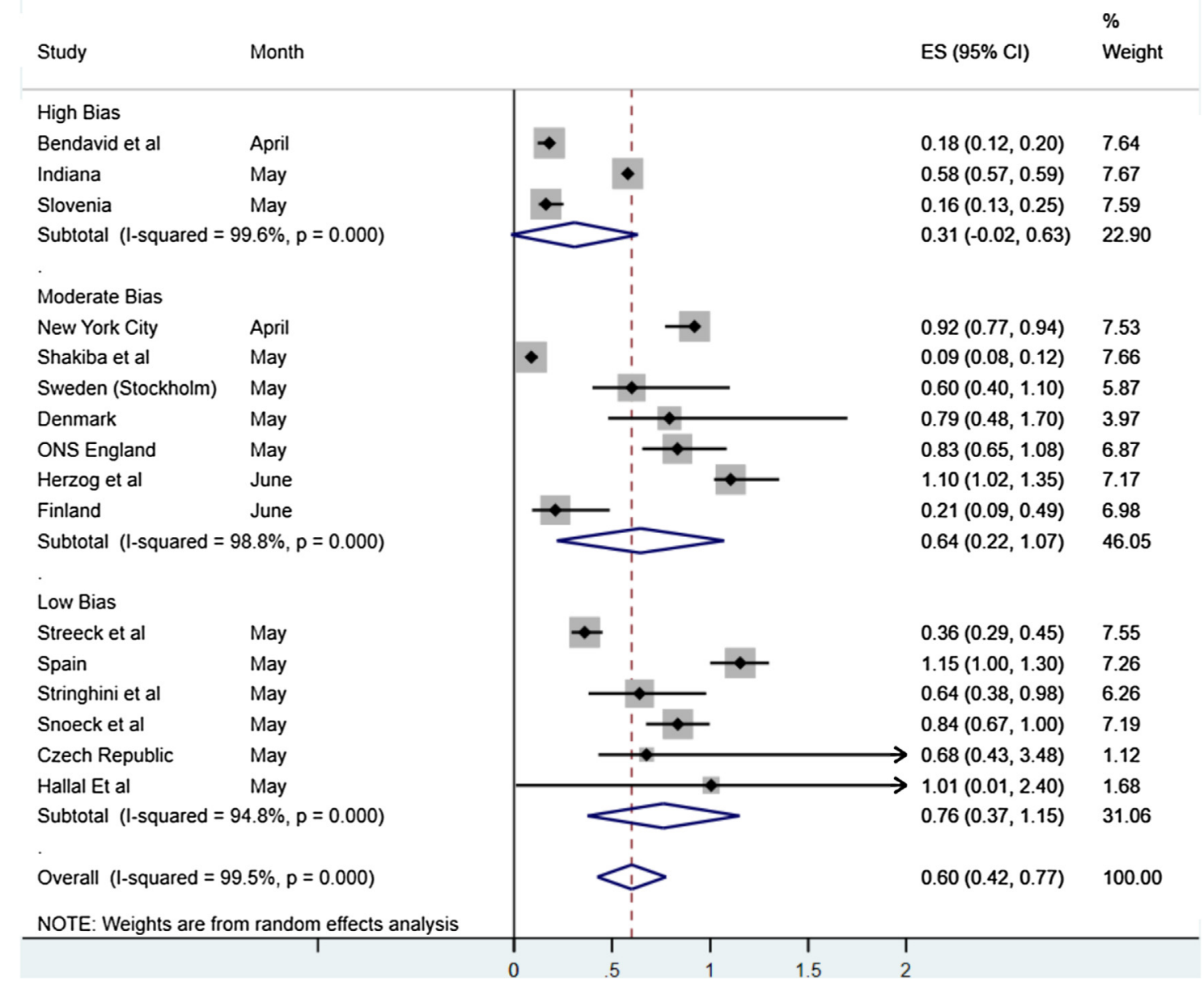

Figure 5.

one case close to 15\% (Modi et al., 2020a). Given the elderly are the most vulnerable in society to illness and likely to carry a higher disease burden owing to increased susceptibility and comorbidity (Liu et al., 2020; Rothan and Byrareddy, 2020), the lower IFRs observed in the younger populations may skew the figure somewhat. There are some reasonable estimates of fatality in younger age groups that were not included in the population estimates (Erikstrup et al., 2020; Valenti et al., 2020; Thompson et al., 2020), which imply a substantially lower rate of death in the population below 70 years of age. While these studies were not considered applicable for quantitative synthesis, they do imply a lower IFR for those aged 18-70 years. Indeed, a recently published estimate stratified infection fatality by age and found a very low risk for under $50 \mathrm{~s}$ that increased exponentially with age from $0.0016 \%<50$ years to $0.14 \%$ for $50-64$ year olds and up to $5.6 \%$ for those 65 years and older (Perez-Saez et al., 2020). This has also been demonstrated in a pre-print meta-analysis of age-stratified IFR that found an exponential increase in IFR by age, from $0.005 \%$ for children to $0.2 \%$ at age $50,0.75 \%$ at age 60 , and $27 \%$ for ages 85 and above (Levin et al., 2020).

While not included in the quantitative synthesis, one paper did examine the extreme lower bound of IFR of COVID-19 in situations where the healthcare system has been overwhelmed. This is likely to be higher than the IFR in a less problematic situation but demonstrates that the absolute minimum in such a situation cannot be lower than $0.2 \%$, and is likely much higher than this figure in most scenarios involving overburdened hospitals.

Of note, there appears to be a divergence between estimates based on serosurveys and those that are modelled or inferred from other forms of testing, with the IFR based purely on serosurveillance being $0.60 \%(0.43 \%-0.77 \%)$. Some have argued that serological surveys are the only proper way to estimate IFR, which would lead to the acceptance of this slightly lower IFR as the most likely estimate (Ioannidis, 2020). However, even these estimates are very heterogeneous in quality, with some extremely robust data such as that reported from the Spanish and Swedish health agencies (Anon, 2020b; Folkhälsomyndigheten, 2020b), and some that have clear and worrying flaws such as a study from Iran where death estimates are reportedly substantially lower than the true figure (Shakiba et al., 2020). However, when taking quality into account, and only analysing those serosurveys that had a low risk of bias, it is interesting to note that the inferred IFR rises substantially to $0.76 \%(0.37 \%-1.15 \%)$. This may be due to the bias in lower-quality serosurveys being towards a higher prevalence (Sood et al., 2020), which in turn lowers the IFR substantially.

Another key issue is accounting for deaths. While official death counts were used for all serosurvey estimates, and included in all modelled estimates, these counts are increasingly being recognized as undercounts of the true death figure (Modi et al., 2020a). Published research is already estimating that, even in many 
wealthy countries with excellent death-reporting systems, more than $50 \%$ of COVID-19 deaths are likely being missed (Modi et al., 2020b; Modig and Ebeling, 2020). It is not unlikely that, after correcting for excess mortality not captured in official deathreporting systems, the IFR of COVID-19 in most populations would be substantially higher than our analysis suggests. It is also possible that the IFR of the disease will drop over time as treatments improve; however, our analysis at least does not demonstrate that this has been the case in the first half of 2020 .

Conversely, there is evidence that the tests used in these serosurveys have drawbacks despite their high specificity and sensitivity. For example, in asymptomatic/mild cases, the tests may have reduced sensitivity, leading to a biased overestimation of the IFR (Takahashi et al., 2020). A recent systematic review and metaanalysis of serological tests for COVID-19 found that even the better serology tests would likely overestimate prevalence in an area with few cases and underestimate prevalence when many people had already been infected (Lisboa Bastos et al., 2020). In areas with a prevalence of $1 \%-2 \%$, for example, the systematic review implies that a study employing an enzyme-linked immunosorbent assay to examine antibodies would produce an estimated infection rate almost double the true prevalence. This would then cause the IFR to be underestimated by the same fraction.

There are a number of limitations to this research. Importantly, the heterogeneity in the meta-analysis was very high. This may mean that the point estimates are less reliable than would be expected. It is also notable that any meta-analysis is only as reliable as the data contained within - this research included a very broad range of studies that address slightly different questions with a very wide range of methodological rigor, and thus cannot represent the certainty of any kind. While modelling studies were not formally graded, at least one has already been critiqued for simple mathematical errors, and given that many were pre-prints, it is hard to ascertain if they have provided accurate representations of the data. Serology studies were at a variable risk of bias, and analysing only the highest quality serosurveys produced a higher estimate than relying on lower quality studies.

Moreover, the quality of included serosurvey estimates was often questionable. Many countries have a clear political motivation to present lower estimates, making it challenging to ascertain whether these may have biased the reporting of results, particularly for those places that have only presented results as press releases thus far. Some have also been criticized for sampling issues that would likely lead to a biased overestimate of population infection rates (Bendavid et al., 2020).

Accounting for right-censoring in these estimates was also a challenge. Using a 10-day cut-off for deaths is far too crude a method to create a reliable estimate. In some cases, this could be an overestimate, due to the seroconversion process taking almost as much time as the median time until death. Conversely, there is a long tail for COVID-19 deaths (Giorgi Rossi et al., 2020), and therefore it is almost certain that some proportion of the 'true' number of deaths will be missed by using a 10-day cut-off, biasing the estimated IFRs down. This may be why serosurvey estimates at first appear to result in somewhat lower IFRs than modelled and observational data suggest.

It is also important to recognize that this is a living estimate. With new data being published every single day during this pandemic, in a wide variety of languages and in innumerable formats, it is impossible to collate every single piece of information into one document no matter how rigorous. Moreover, this aggregated estimate is only as correct as the most recent search - the point estimate has not shifted substantially because of the inclusion of new research, but the confidence interval has changed. It is almost certain that, over the course of coming months and years, the IFR will be revised a number of times. In particular, it is vital that future research stratifies this estimate by age, as this appears to be the most significant factor in the risk of death from COVID-19.

This research has a range of very important implications. Some countries have announced the aim of pursuing herd immunity with regard to COVID-19 in the absence of a vaccination. The aggregated IFR would suggest that, at a minimum, you would expect $0.45 \%-0.53 \%$ of a population to die before the herd immunity threshold of the disease (based on R0 of 2.5-3 (Russell et al., 2020)) was reached (Mahase, 2020). As an example, in the US this would imply more than 1 million deaths at the lower end of the scale. Even with a lower herd immunity threshold suggested by more recent modelling (Aguas et al., 2020), this would imply an unmanageable number of deaths to reach the threshold across a country.

This also has implications for future planning. Governments looking to exit lockdowns should be prepared to see a relatively high IFR within the population that is infected if COVID-19 reemerges. This should inform the decision to relax restrictions, given that the IFR for people infected with COVID-19 appears to be not insignificant even in places with very robust healthcare systems.

\section{Conclusions}

Based on a systematic review and meta-analysis of published evidence on COVID-19 until July 2020, the IFR of the disease across populations is $0.68 \%(0.53 \%-0.82 \%)$. However, because of very high heterogeneity in the meta-analysis, it is difficult to know if this represents the 'true' point estimate. In particular, higher quality serosurveys with lower risk of bias appeared to generate higher IFRs. It is likely that, because of age and perhaps underlying comorbidities in the population, different places will experience different IFRs due to the disease. Given the issues with mortality recording, it is also likely that this represents an underestimate of the true IFR figure. More research looking at age-stratified IFR is urgently needed to inform policymaking on this front.

Authors' declarations

The authors declare no conflicts of interest. No funding was received for this study. A pre-print version can be found here: https://www.medrxiv.org/content/10.1101/

2020.05.03.20089854v1.

No ethical approval was sought for this study.

\section{Appendix A. Supplementary data}

Supplementary material related to this article can be found, in the online version, at doi:https://doi.org/10.1016/j.ijid.2020.09.1464.

\section{References}

Aguas R, Corder RM, King JG, Goncalves G, Ferreira MU, Gomes MGM. Herd immunity thresholds for SARS-CoV-2 estimated from unfolding epidemics. medRxiv 2020; 2020.07.23.20160762.

Variation in false-negative rate of reverse transcriptase polymerase chain reactionbased SARS-CoV-2 tests by time since exposure. Ann Intern Med; O(0):null.

Anon. ESTUDIO NACIONAL DE SERO-EPIDEMIOLOGÍA DE LA INFECCIÓN POR SARSCOV-2 EN ESPAÑA. Instituto de Salud Carlos III; 2020.

Anon. Collective immunity study SARS-COV-2-CZ-Preval: preliminary results. Czech Republic Ministry of Health; 2020.

Anon. Weekly Report of the Population Serology Survey of the Corona Epidemic. Finland: Finnish Government; 2020.

Bai Y, Yao L, Wei T, Tian F, Jin D-Y, Chen L, et al. Presumed asymptomatic carrier transmission of COVID-19. JAMA 2020;323(14):1406-7.

Bassett BA. Strict lower bound on the COVID-19 fatality rate in overwhelmed healthcare systems. medRxiv 2020; 2020.04.22.20076026.

Basu A. Estimating the infection fatality rate among symptomatic COVID-19 cases in the United States. Health Aff (Project Hope) 2020; 101377hlthaff202000455. 
Bendavid E, Mulaney B, Sood N, Shah S, Ling E, Bromley-Dulfano R, et al. COVID-19 antibody seroprevalence in Santa Clara County, California. medRxiv 2020; 2020.04.14.20062463.

Bryan A, Pepper G, Wener MH, Fink SL, Morishima C, Chaudhary A, et al. Performance characteristics of the Abbott Architect SARS-CoV-2 IgG assay and seroprevalence in Boise, Idaho. J Clin Microbiol 2020; JCM.00941-20.

Doi A, Iwata K, Kuroda H, Hasuike T, Nasu S, Kanda A, et al. Estimation of seroprevalence of novel coronavirus disease (COVID-19) using preserved serum at an outpatient setting in Kobe, Japan: a cross-sectional study. medRxiv 2020; 2020.04.26.20079822.

Dong E, Du H, Gardner L. An interactive web-based dashboard to track COVID-19 in real time. Lancet Infect Dis 2020;20(5):533-4.

Ed Slot BMH, Reusken Chantal BEM, et al. Herd immunity is not a realistic exit strategy during a COVID-19 outbreak. Epidemiology 2020; 28 April 2020, PREPRINT (Version 1) available at Research Square [+https://doi.org/10.21203/ rs.3.rs-25862/v1+]. In Review.

Erikstrup C, Hother CE, Pedersen OBV, Mølbak K, Skov RL, Holm DK, et al. Estimation of SARS-CoV-2 infection fatality rate by real-time antibody screening of blood donors. medRxiv 2020; 2020.04.24.20075291.

Fernández-Barat L, López-Aladid R, Torres A. The value of serology testing to manage SARS-CoV-2 infections. Eur Respir J 2020;2002411.

Folkhälsomyndigheten. The infection fatality rate of COVID-19 in Stockholm technical report. Sweden: Public Health Agency of Sweden; 2020.

Folkhälsomyndigheten, editor. Första resultaten från pågående undersökning av antikroppar för covid-19-virus. Sweden: Folkhälsomyndigheten; 2020.

Fontanet A, Tondeur L, Madec Y, Grant R, Besombes C, Jolly N, et al. Cluster of COVID19 in northern France: a retrospective closed cohort study. medRxiv 2020; 2020.04.18.20071134.

Garcia-Basteiro AL, Moncunill G, Tortajada M, Vidal M, Guinovart C, Jimenez A, et al. Seroprevalence of antibodies against SARS-CoV-2 among health care workers in a large Spanish reference hospital. medRxiv 2020; 2020.04.27.20082289.

Ghaffari A, Meurant R, Ardakani A. COVID-19 serological tests: how well do they actually perform?. Diagnostics 2020;10(7):453.

Giorgi Rossi P, Emilia-Romagna COVID-19 working group, Broccoli S, Angelini P. Case fatality rate in patients with COVID-19 infection and its relationship with length of follow up. J Clin Virol 2020;128:104415.

Grewelle R, De Leo G. Estimating the global infection fatality rate of COVID-19. medRxiv 2020; 2020.05.11.20098780.

Gudbjartsson DF, Helgason A, Jonsson H, Magnusson OT, Melsted P, Norddahl GL, et al. Spread of SARS-CoV-2 in the Icelandic population. N Engl J Med 2020;

Hallal P, Hartwig F, Horta B, Victora GD, Silveira M, Struchiner C, et al. Remarkable variability in SARS-CoV-2 antibodies across Brazilian regions: nationwide serological household survey in 27 states. medRxiv 2020; 2020.05.30.20117531.

Herzog S, De Bie J, Abrams S, Wouters I, Ekinci E, Patteet L, et al. Seroprevalence of IgG antibodies against SARS coronavirus 2 in Belgium: a serial prospective cross-sectional nationwide study of residual samples. medRxiv 2020; 2020.06.08.20125179.2.

Hoy D, Brooks P, Woolf A, Blyth F, March L, Bain C, et al. Assessing risk of bias in prevalence studies: modification of an existing tool and evidence of interrater agreement. J Clin Epidemiol 2012;65(9):934-9.

Institut SS, editor. Notat: Foreløbige resultater fra den repræsentative seroprævalensundersøgelse af COVID-19. Denmark: Statens Serum Institut; 2020.

Ioannidis J. The infection fatality rate of COVID-19 inferred from seroprevalence data. medRxiv 2020; 2020.05.13.20101253.

IU. ISDH release preliminary findings about impact of COVID-19 in Indiana. Indiana: Indiana University; 2020.

Jason Oke CH. Global Covid-19 case fatality rates. Centre for Evidence-Based Medicine: University of Oxford; 2020.

Jerkovic I, Ljubic T, Basic Z, Kruzic I, Kunac N, Bezic J, et al. SARS-CoV-2 antibody seroprevalence in industry workers in Split-Dalmatia and Sibenik-Knin County, Croatia. medRxiv 2020; 2020.05.11.20095158.

Jung SM, Akhmetzhanov AR, Hayashi K, Linton NM, Yang Y, Yuan B, et al. Real-time estimation of the risk of death from novel coronavirus (COVID-19) infection: inference using exported cases. J Clin Med 2020;9(2).

Kahathuduwa CN, Dhanasekara CS, Chin S-H. Case fatality rate in COVID-19: a systematic review and meta-analysis. medRxiv 2020; 2020.04.01.20050476.

Levin AT, Meyerowitz-Katz G, Owusu-Boaitey N, Cochran KB, Walsh SP. Assessing the age specificity of infection fatality rates for COVID-19: systematic review, meta-analysis, and public policy implications. medRxiv 2020; 2020.07.23.20160895.

Lisboa Bastos M, Tavaziva G, Abidi SK, Campbell JR, Haraoui L-P, Johnston JC, et al. Diagnostic accuracy of serological tests for covid-19: systematic review and meta-analysis. BMJ 2020;370:m2516.

Liu K, Chen Y, Lin R, Han K. Clinical features of COVID-19 in elderly patients: a comparison with young and middle-aged patients. J Infect 2020; S0163-4453 (20)30116-X.

Mahase E. Covid-19: UK starts social distancing after new model points to 260000 potential deaths. BMJ 2020;368(1089).

Modi C, Boehm V, Ferraro S, Stein G, Seljak U. Total COVID-19 mortality in italy: excess mortality and age dependence through time-series analysis. medRxiv 2020a: 2020.04.15.20067074.

Modi C, Boehm V, Ferraro S, Stein G, Seljak U. How deadly is COVID-19? A rigorous analysis of excess mortality and age-dependent fatality rates in Italy. medRxiv 2020b; 2020.04.15.20067074.

Modig K, Ebeling M. Excess mortality from COVID-19. Weekly excess death rates by age and sex for Sweden. medRxiv 2020; 2020.05.10.20096909.
Nishiura H, Kobayashi T, Yang Y, Hayashi K, Miyama T, Kinoshita R, et al. The rate of underascertainment of novel coronavirus (2019-nCoV) infection: estimation using Japanese passengers data on evacuation flights. J Clin Med 2020;9(2).

Perez-Saez J, Lauer SA, Kaiser L, Regard S, Delaporte E, Guessous I, et al. Serologyinformed estimates of SARS-COV-2 infection fatality risk in Geneva, Switzerland. medRxiv 2020; 2020.06.10.20127423.

Rinaldi G, Paradisi M. An empirical estimate of the infection fatality rate of COVID19 from the first Italian outbreak. medRxiv 2020; 2020.04.18.20070912.

Roques L, Klein E, Papaix J, Sar A, Soubeyrand S. Using early data to estimate the actual infection fatality ratio from COVID-19 in France. medRxiv 2020; 2020.03.22.20040915.

Rothan HA, Byrareddy SN. The epidemiology and pathogenesis of coronavirus disease (COVID-19) outbreak. J Autoimmun 2020;109:102433.

Russell TW, Hellewell J, Jarvis CI, van Zandvoort K, Abbott S, Ratnayake R, et al. Estimating the infection and case fatality ratio for coronavirus disease (COVID19) using age-adjusted data from the outbreak on the Diamond Princess cruise ship, February 2020. Euro Surveill 2020;25(12).

Salje H, Tran Kiem C, Lefrancq N, Courtejoie N, Bosetti P, Paireau J, et al. Estimating the burden of SARS-CoV-2 in France. Science 2020; eabc3517.

Scally G, Jacobson B, Abbasi K. The UK's public health response to covid-19. BM] 2020;369:m1932.

Shakiba M, Hashemi Nazari SS, Mehrabian F, Rezvani SM, Ghasempour Z, Heidarzadeh A. Seroprevalence of COVID-19 virus infection in Guilan province, Iran. medRxiv 2020; 2020.04.26.20079244.

Silveira M, Barros A, Horta B, Pellanda L, Victora G, Dellagostin O, et al. Repeated population-based surveys of antibodies against SARS-CoV-2 in Southern Brazil. medRxiv 2020; 2020.05.01.20087205.

Simon P. Robust estimation of infection fatality rates during the early phase of a pandemic. medRxiv 2020; 2020.04.08.20057729.

Slovenia RO, editor. First study carried out on herd immunity of the population in the whole territory of Slovenia. Slovenia: Republic of Slovenia; 2020.

Snoeck CJ, Vaillant M, Abdelrahman T, Satagopam VP, Turner JD, Beaumont K, et al. Prevalence of SARS-CoV-2 infection in the Luxembourgish population: the CONVINCE study. medRxiv 2020; 2020.05.11.20092916.

Sood N, Simon P, Ebner P, Eichner D, Reynolds J, Bendavid E, et al. Seroprevalence of SARS-CoV-2-specific antibodies among adults in Los Angeles County, California, on April 10-11, 2020. JAMA 2020;.

Spychalski P, Błażyńska-Spychalska A, Kobiela J. Estimating case fatality rates of COVID-19. Lancet Infect Dis 2020;.

Staines HM, Kirwan DE, Clark DJ, Adams ER, Augustin Y, Byrne RL, et al. Dynamics of IgG seroconversion and pathophysiology of COVID-19 infections. medRxiv 2020; 2020.06.07.20124636.

Statistics OFN, editor. Coronavirus (COVID-19) Infection Survey pilot: 5 June 2020 England: Office for National Statistics; 2020.

Streeck H, Schulte B, Kuemmerer B, Richter E, Hoeller T, Fuhrmann C, et al. Infection fatality rate of SARS-CoV-2 infection in a German community with a superspreading event. medRxiv 2020; 2020.05.04.20090076.3.

Stringhini S, Wisniak A, Piumatti G, Azman AS, Lauer SA, Baysson H, et al. Repeated seroprevalence of anti-SARS-CoV -2 IgG antibodies in a population-based sample from Geneva, Switzerland. medRxiv 2020a; 2020.05.02.20088898.

Stringhini S, Wisniak A, Piumatti G, Azman AS, Lauer SA, Baysson H, et al. Seroprevalence of anti-SARS-CoV-2 IgG antibodies in Geneva, Switzerland (SEROCoV-POP): a population-based study. Lancet 2020b;

Sutton D, Fuchs K, D’Alton M, Goffman D. Universal screening for SARS-CoV-2 in women admitted for delivery. N Engl J Med 2020;.

Takahashi S, Greenhouse Bryan, Rodríguez-Barraquer Isabel. Are Sars-cov-2 seroprevalence estimates biased?. OSF Preprints; 2020.

Takita M, Matsumura T, Yamamoto K, Yamashita E, Hosoda K, Hamaki T, et al. Preliminary results of seroprevalence of SARS-CoV-2 at community clinics in Tokyo, medRxiv 2020; 2020.04.29.20085449.

Thompson WW, Moore MR, Weintraub E, Cheng P-Y, Jin X, Bridges CB, et al. Estimating influenza-associated deaths in the United States. Am J Public Health 2009;99(S2):S225-30.

Thompson C, Grayson N, Paton R, Lourenço J, Penman B, Lee LN, et al. Neutralising antibodies to SARS coronavirus 2 in Scottish blood donors - a pilot study of the value of serology to determine population exposure. medRxiv 2020; 2020.04.13.20060467.

Tian S, Hu N, Lou J, Chen K, Kang X, Xiang Z, et al. Characteristics of COVID-19 infection in Beijing. J Infect 2020;80(4):401-6.

Valenti L, Bergna A, Pelusi S, Facciotti F, Lai A, Tarkowski M, et al. SARS-CoV-2 seroprevalence trends in healthy blood donors during the COVID-19 Milan outbreak. medRxiv 2020; 2020.05.11.20098442.

Verity R, Okell LC, Dorigatti I, Winskill P, Whittaker C, Imai N, et al. Estimates of the severity of coronavirus disease 2019: a model-based analysis. Lancet Infect Dis 2020:

Villa M, Myers JF, Turkheimer F. COVID-19: recovering estimates of the infected fatality rate during an ongoing pandemic through partial data. medRxiv 2020; 2020.04.10.20060764

Wilson L. SARS-CoV-2, COVID-19, Infection Fatality Rate (IFR) implied by the serology, antibody, testing in New York City. SSRN; 2020.

Winter AK, Hegde ST. The important role of serology for COVID-19 control. Lancet Infect Dis 2020;.

Wong JY, Wu P, Nishiura H, Goldstein E, Lau EHY, Yang L, et al. Infection fatality risk of the pandemic A(H1N1)2009 virus in Hong Kong. Am J Epidemiol 2013;177 (8):834-40.

Xiao AT, Tong YX, Zhang S. False-negative of RT-PCR and prolonged nucleic acid conversion in COVID-19: rather than recurrence. J Med Virol; n/a (n/a). 